\title{
The Influence of Moral Character Attributes on Adolescent Life Satisfaction: the Mediating Role of Responsible Behavior
}

\author{
Zheng Zhou' ${ }^{1} \cdot$ Daniel T. L. Shek ${ }^{2} \oplus \cdot$ Xiaoqin Zhu² $^{2} \cdot$ Li Lin $^{2}(0$
}

Accepted: 11 December 2020 / Published online: 4 February 2021

(c) The Author(s) 2021

\begin{abstract}
In this pioneering study, we examined the influence of moral character attributes and responsible behavior on adolescent life satisfaction, as well as the mediating role of adolescents' responsible behavior in the influence of moral character attributes on life satisfaction in 2,474 adolescents in Hong Kong. We used a 25-item measure to assess moral character attributes, a 15-item measure to assess responsible behavior, and the 5-item Satisfaction with Life Scale to assess life satisfaction. Factor analyses using confirmatory factor analyses provided support for the factorial validity of the measures of adolescent moral character attributes, responsible behavior, and life satisfaction. Consistent with our hypotheses, moral character attributes positively predicted adolescents' responsible behavior as well as life satisfaction, and adolescents' responsible behavior positively predicted life satisfaction. Separate analyses using PROCESS and combined analysis using SEM via Mplus showed that adolescents' responsible behavior mediated the influence of moral character attributes on adolescent life satisfaction. The present findings highlight the importance of moral character on adolescent well-being and support the positive youth development approach in the field.
\end{abstract}

Keywords Moral character $\cdot$ Responsible behavior $\cdot$ Life satisfaction $\cdot$ Well-being · Chinese adolescents

Daniel T. L. Shek

daniel.shek@polyu.edu.hk

1 Research Institute of Social Development, Southwestern University of Finance and Economics, Chengdu, People's Republic of China

2 Department of Applied Social Sciences, The Hong Kong Polytechnic University, Hunghom, Hong Kong, People's Republic of China 


\section{Introduction}

It is essential for human beings to achieve a good state of well-being or a flourishing life (Seligman 2002; Seligman and Csikszentmihalyi 2000). From the perspective of positive psychology, well-being is a multidimensional construct, including cognitive components such as life satisfaction and emotional component such as subjective feelings (Diener et al. 1999). For subjective well-being, life satisfaction is a commonly used measure as it reflects how individuals judge the overall quality of their life. Life satisfaction has drawn much attention from researchers because it is closely related to different aspects of health, including physical health (Howell et al. 2007) as well as mental and social health (Marks and Fleming 1999).

Regarding correlates of life satisfaction, although studies showed that characterrelated factors (Porubanova-Norquist 2012) and prosocial behavior were associated with well-being (Alden and Trew 2013; Dou et al. 2019), there is a lack of studies examining the mechanisms of how adolescent moral character attributes and prosocial behavior (such as responsible behavior) influence life satisfaction with prosocial behavior as a mediating factor. A computer search of PsycINFO in November 2020 using "character", "prosocial", and "life satisfaction" as the search terms showed that there were only 13 citations (and one citation when "Chinese" was added as a search term). Hence, the present study attempted to address this research gap by investigating the influence of adolescent moral character attributes and prosocial behavior (indexed by responsible behavior) on life satisfaction and the mediating role of responsible behavior.

Previous studies showed that personality and character variables accounted for most of the variance in well-being measures (Diener 1996). Compared to temperament, which is more related to hedonic well-being, character is more associated with eudaimonic well-being (Cloninger 2004). According to Porubanova-Norquist (2012), character is “one's self-government, as it modulates the leverage of unconscious or preconscious automatic percepts and affects managed by temperament by assigning meaning to them" (p. 231). Cloninger et al. (1993) identified three dimensions of character, including "self-directedness", "cooperativeness", and "selftranscendence"; Cloninger (2008) also regarded character as higher-order sociocognitive processes, including "self-concepts", "goals", and "values". In addition to the observation that personality was related to well-being in adults (Costa and McCrae 1980; DeNeve and Cooper 1998), Porubanova-Norquist (2012) showed that self-directedness and cooperativeness had significant associations with well-being in adolescents. Research findings support the relationship between character and adolescent well-being in different places as well (Cloninger et al. 1993; Josefsson et al. 2011; Porubanova-Norquist 2012). For example, based on 1,540 adolescents, Moreira and colleagues (Moreira et al. 2015) found that self-directedness was associated with both affective and cognitive well-being, and cooperativeness was significantly associated with cognitive well-being and positive affect.

Comparatively speaking, fewer studies have examined the relationship between character attributes defined by morality and virtues (i.e., moral character attributes) and life satisfaction. For example, Schwartz and Sortheix (2018) pointed out 
that "research on relations of personal values to subjective well-being has begun to flourish only recently" (p. 1). According to Aquino and Reed (2002), moral character can be conceptualized as a set of moral traits that a person should possess, and it is central to an individual's moral identities.

From the perspective of character education, the promotion of moral virtues such as respect, loyalty, responsibility, self-control, and compassion should be the aim of moral education (Park 2004). Aquino and Reed (2002) identified nine moral character traits that form a moral identity, including care, compassion, fairness, friendliness, generosity, helpfulness, diligence, honesty, and kindness. Hardy et al. (2014) further identified 20 moral character attributes in a "moral person", such as generosity, loyalty, respect, and compassion. Findings suggest that moral ideal self leads to positive adolescent outcomes, such as lower problematic behaviors, higher environmentalism, and higher school engagement (Hardy et al. 2014). Moral character attributes, including hope, zest, love, social intelligence, and perseverance, were also positively related to adult life satisfaction (Martínez-Martí and Ruch 2014). Schwartz and Sortheix (2018) proposed ten broad values, including "achievement", "power", "security", “conformity", "tradition", "benevolence", "universalism", "self-direction", "stimulation", and "hedonism". Peterson and Seligman (2004) identified six virtues, including 24 character strengths, such as forgiveness, kindness, fairness, prudence, and selfregulation. In general, the above-mentioned moral characters commonly emphasize two aspects of morality, including treating others well and self-regulation.

Conceptually speaking, although there are common moral virtues across different cultures and regions, cultural variation of morality exists (Liu et al. 2016; Shek and Zhu 2019). In Chinese culture, Chinese morality has been primarily based on traditional Confucian thoughts (Shek et al. 2013), emphasizing the importance of moral order and interpersonal harmony. In terms of social values, Chinese college students scored higher on collectivistic values that emphasize respecting in-group norms and prioritizing group-interest ahead of self-interest compared with college students from the United States (Chiou 2001). In addition, research on adolescent moral competence showed that Chinese adolescents scored higher on self-regulation, modesty, and prudence than on curiosity, humor, and gratitude (Liu et al. 2016). In contrast, Western adolescents' kindness, gratitude, and integrity scores were higher than their modesty, persistence, and selfregulation (Park and Peterson 2006). These studies suggest that it is necessary to take cultural context into consideration when conceptualizing and assessing moral character attributes. Therefore, according to the previous research, moral character of Chinese adolescents should not only include treating others well and self-regulation, but also traditional Chinese virtues (Chai et al. 2020).

Theoretically, models in the positive youth development (PYD) literature regard moral character attributes as important determinants of adolescent wellbeing. For example, Lerner's 5C/6C models maintain that well-being is shaped by moral character (Lerner et al. 2011). The developmental assets framework also highlights the importance of positive values (such as moral character and virtues) in shaping adolescent well-being (Benson et al. 2011). Based on the limited empirical evidence in the field and related theoretical accounts, it was 
expected that moral character attributes would be positively associated with life satisfaction.

Having a sense of social responsibility is a significant dimension of moral character, which can be conceived as a set of prosocial values to improve the society with the concern for the greater goods and others' welfare beyond personal interests (Gallay 2006; Wray-Lake et al. 2016). It is also a form of prosocial orientation and a tendency to help others even when nothing will be given back from them (Berkowitz and Lutterman 1968), as well as emphasizing moral principles of justice (Berman 1997). According to Wray-Lake and Syvertsen (2011), social responsibility develops from childhood to adulthood, coinciding with or following the development of emotional foundation (e.g., empathy), cognitive ability (e.g., executive functioning skills), as well as self and identity. During adolescence, individuals develop a sense of agency and responsibility and recognize the responsibility of their actions and concern for the consistency of their behavior and self-conception (Hardy and Carlo 2011). Hardy et al. (2014) argued that social responsibility is a component of moral identity that can be conceived in terms of perceived moral traits.

Damon and Hart (1992) showed that moral identity in terms of moral traits was related to responsible behavior. Blasi (1993) proposed that the component of one's identity leads to the feelings of responsibility to act, and moral identity drives people to respond to others' needs (Aquino and Reed 2002). Hardy and colleagues (Hardy et al. 2014) further showed that adolescent moral identity was a significant indicator of their responsible behaviors, such as more frequent engagement of environmentally friendly and school activities in the past year. Aquino and Reed (2002) showed that people with a stronger moral identity were more likely to engage in moral activities with an aim to promote others' welfare, such as taking part in voluntary activities or helping youth in trouble. Pratt et al. (2009) further showed that the salience of moral identity at adolescence predicted an individual's later responsible behavior, such as community service engagement. Theoretically, PYD models, such as Lerner's 5C/6C model (Lerner et al. 2011) and Benson's developmental assets model (Benson et al. 2011), suggest that moral character is the basis for prosocial behavior such as performing responsible behavior (Shek et al. 2019). Hence, it was expected that moral character attributes would be positively related to adolescent prosocial behavior indexed by responsible behavior.

Research findings also showed that prosocial behavior was related to well-being (Garcia et al. 2015). Brethel-Haurwitz and Marsh (2014) reported that adult kind behavior was associated with well-being. Experimental studies also suggested that acting prosaically could promote individual well-being, such as positive affect (Alden and Trew 2013) and social relationship quality (O'Connell et al. 2015). Based on a study of early adolescents, Cotney and Banerjee (2019) reported that kindness contributed to adolescent well-being no matter they are the givers or recipients. With reference to different PYD models, it is suggested that engagement in prosocial behavior, such as responsible behavior, promotes life satisfaction. For example, some of the developmental assets proposed by Benson et al. (2011), such as empowerment (e.g., service to the community), commitment to learning (e.g., doing homework), and "positive values" (e.g., accepts and take responsibility), can be regarded as responsible behavior leading to positive adolescent development. 
Moreover, a recent study on Chinese adolescents and adults found that prosocial behavior partly mediated the relationship between self-control and life satisfaction, with higher levels of self-control leading to more prosocial behavior, and subsequently, greater life satisfaction (Dou et al. 2019). Based on the literature, it was expected that acting in a responsible manner (e.g., completing one's homework, doing housework, and showing concerns to the community) would be positively related to life satisfaction.

Several research gaps can be highlighted from the scientific literature on the influence of moral character attributes and responsible behavior on adolescent life satisfaction. First, although there are studies on the effects of personality and character traits on individual well-being (Diener 1996; Emmons and Diener 1985; Porubanova-Norquist 2012), there are few studies investigating the relationship between "moral character" attributes and well-being. Second, although there are some studies on the relationship between prosocial behavior and adult well-being (Alden and Trew 2013), studies on the influence of adolescent social responsibility on life satisfaction are still very limited (Cotney and Banerjee 2019). Third, no study has to date examined the mediating effect of adolescents' socially responsible behavior on the influence of moral character attributes on well-being. As pointed out by Soares et al. (2019), "a review of literature showed few studies addressing the relationship between perceived life satisfaction and developmental assets in the context of positive youth development approach" (p.3). Fourth, most of the previous studies were conducted in Western contexts. As the Chinese population is huge and moral character is strongly emphasized in the Chinese culture (Shek and Zhu 2019), it is crucial to understand the role of moral character attributes and responsible behavior on Chinese adolescents' life satisfaction. Fifth, in view of the social protests taking place in Hong Kong, which were associated with violent behavior in some of the protestors, it is theoretically and practically important to understand how moral character attributes and responsible behavior are related to adolescent well-being (Shek 2020). Finally, as there is no validated measure of moral character attributes for high school students in the Hong Kong context, there is a need to develop and validate the related measures.

\subsection{The Present Study}

To address the above research gaps, we conducted a cross-sectional study to examine several research questions as follows:

Research Question 1: Are moral character attributes related to adolescent life satisfaction?

Research Question 2: Are moral character attributes related to adolescent prosocial behavior indexed by responsible behavior?

Research Question 3: Is adolescent's responsible behavior related to adolescent life satisfaction?

Research Question 4: Does adolescent's responsible behavior mediate the influence of moral character attributes on life satisfaction? 
Based on PYD theories and previous research, it was expected that: a) moral character attributes would be positively related to adolescent life satisfaction (Hypothesis 1), b) moral character attributes would be positively related to adolescent prosocial behavior indexed by responsible behavior (Hypothesis 2), and c) adolescents' responsible behavior would be positively related to adolescent life satisfaction (Hypothesis 3). In addition, based on previous literature, we also hypothesized that adolescents' responsible behavior would mediate the influence of responsible behavior on adolescent life satisfaction (Hypothesis 4).

\section{Methods}

\subsection{Participants and Procedure}

The data used in this study were derived from a cross-sectional project entitled "Character Building - A shared mission for a better future" funded by Wofoo Foundation in which data were collected from adolescents, parents, and teachers in Hong Kong. This project attempted to understand the moral character development of adolescents in Hong Kong, including their moral character attributes, psychosocial competence, responsible behavior, and well-being from different perspectives. In the present study, findings based on high school students were reported. The data were collected from 20 schools admitting students with different academic performance. In each participating school, three to five classes were randomly selected to join the project. In total, 2,474 students (Mage $=14.76 \pm 1.82$ years; 1,123 boys and 1,271 girls) participated in the study, among whom 1,468 (60.06\%) were junior high school students and 988 (39.94\%) were senior high school students.

The project was approved by the "Human Subjects Ethics Sub-Committee" in the affiliated university of the corresponding author. Written consent was obtained from the participating school, student participants, and their parents prior to data collection. During data collection, students responded to a battery of questionnaires measuring their traits, behavior, and well-being. Students were given enough time to complete all the measures with the presence of a trained research assistant.

\subsection{Measures Used in the Present Study}

\subsubsection{Moral Character}

Participants' perceived moral character was measured by the 25 -item Personal Moral Character Scale (PMCS) based on an integration of the existing literature (Aquino and Reed 2002; Chen 2008; Schwartz 1992). First, nine items (i.e., "caring", "compassionate", "fair", "friendly", "generous", "hardworking", "helpful", "honest", and "kind") were derived from moral identity measure developed by Aquino and Reed (2002). This scale has been validated in Chinese adolescents (Wan and Yang 2008) and university students (Yang et al. 2015). Second, an additional 10 items (i.e., respecting others, obeying the law, dedicated, self-disciplined, self-respected, 
thrift, modest, having personal cultivation, authentic, and polite) were selected from Chen's (2008) Moral Values subscale of the Adolescents' Values Scale. This scale was developed in a Chinese context and has been successfully used in Chinese samples (e.g., Yang et al. 2015) and American samples (e.g., Stoeber and Yang 2016). Finally, six more attributes were selected and adapted based on the Schwartz Values Survey (Schwartz and Shalom 2009), which has been repeatedly used in Chinese contexts (e.g., Schwartz 1992). These attributes were deemed to be morally valued in Chinese culture by the research team, which include loyalty, responsibility, forgiving, having a sense of justice, honoring parents and elders, and respect for tradition.

Conceptually speaking, three categories of moral character attributes are intrinsic to these 25 items, including treating others well (friendly, generous, helpful, kind, sincere, respectful, willing to contribute, caring, compassionate, and having selfesteem), self-discipline and law abidance (fair, hard-working, honest, law-abiding, self-discipline, modest, simple and unadorned and educated), and traditional Chinese virtues (polite, loyal, sense of responsibility, forgiving, sense of justice, respect for the elderly, and respect of traditional culture). Participants were asked to evaluate themselves based on these 25 attributes by reporting the degree to which each moral attribute was true of their character attributes on a 5-point Likert scale ("1 = not true at all; $5=$ highly true"). The internal consistency of this scale was good (Cronbach's $\alpha=0.93$; mean item-item correlation $=0.36$; mean item-total correlation $=0.58$ ).

\subsubsection{Adolescent Responsible Behavior}

In the study, we developed a measure of adolescents' responsible behavior with reference to the research conducted by the Centre for Governance and Citizenship (2004), where Hong Kong high school students were asked to list ten responsibilities that were important to them. The results yielded 13 kinds of responsibilities in the domains of self (e.g., self-discipline), interpersonal relationship (e.g., respect others), family (e.g., do housework), society (e.g., care about the community and Hong Kong), country (e.g., love one's country), the world (e.g., care about the world) and religion (e.g., religion responsibility). We did not include the item about religion as such responsibility is limited to people with religious beliefs. The items containing two meaningful units were decomposed into two items. Additionally, we added two items that represent responsibility in the domains of the family (i.e., maintain family harmony) and society (i.e., maintain societal harmony). The 15 items formed the Adolescents' Responsible Behavior Scale (ARBS). Participants were requested to evaluate their performance on fulfilling 15 kinds of responsibilities on a 5-point Likert scale (" $1=$ very poor; $5=$ very good"). The internal consistency of this scale was good (Cronbach's $\alpha=0.89$; mean inter-item correlation $=0.34$; mean item-total correlation $=0.55)$.

\subsubsection{Life Satisfaction}

Life satisfaction has commonly been used to measure subjective well-being (Chopik et al. 2017; Karabati and Cemalcilar 2010; Sortheix et al. 2013; Sortheix and Schwartz 2017). Previous studies have also examined the relationship between 
character and well-being indexed by life satisfaction (Garcia 2011; Moreira et al. 2015). In the present study, as the cognitive component of subjective well-being, life satisfaction was measured by the 5-item "Satisfaction with Life Scale" (Diener et al. 1985). The respondents rated the five statements (e.g., "the conditions of my life are excellent" and "I am satisfied with my life") about their life quality from 1 ("strongly disagree") to 6 ("strongly agree"). The Chinese version of the scale has been widely adopted in measuring life satisfaction among Chinese people (Shek et al. 2017; Zhu and Shek 2020a). In this study, the Cronbach's $\alpha$ of the scale was 0.87 (mean interitem correlation $=0.58$ and mean item-total correlation $=0.70$ ), suggesting good internal consistency of the scale.

\subsubsection{Control Variables}

Control variables included adolescents' age, gender, family intactness, and economic situation. For family intactness, the first marriage of their parents indicated an intact family while other marital status of parents (i.e., second marriage, separation, or divorce) represented a non-intact family. A total of 1,785 (72.15\%) respondents were living in intact families. A student was regarded as having family economic disadvantage if his or her family was living on governmental welfare. In this case, $239(9.66 \%)$ students had family economic disadvantage.

\subsection{Data Analytic Plan}

To measure moral character attributes, both exploratory and confirmatory factor analyses (EFA and CFA) were carried out to examine whether the findings supported the three dimensions of the scale (i.e., other related attributes, self-discipline and law abidance, and traditional Chinese values). We also conducted a CFA to test the single-factor structure for the measures of responsible behavior and life satisfaction.

For the relationships amongst moral character attributes, responsible behavior, and life satisfaction, a correlational analysis was performed using SPSS 25.0. To investigate the hypothesized relationships among the key variables, we employed PROCESS macro in SPSS (Hayes 2018) to test the mediation model depicted in Fig. 1. As there are three domains on moral character, three separate analyses were

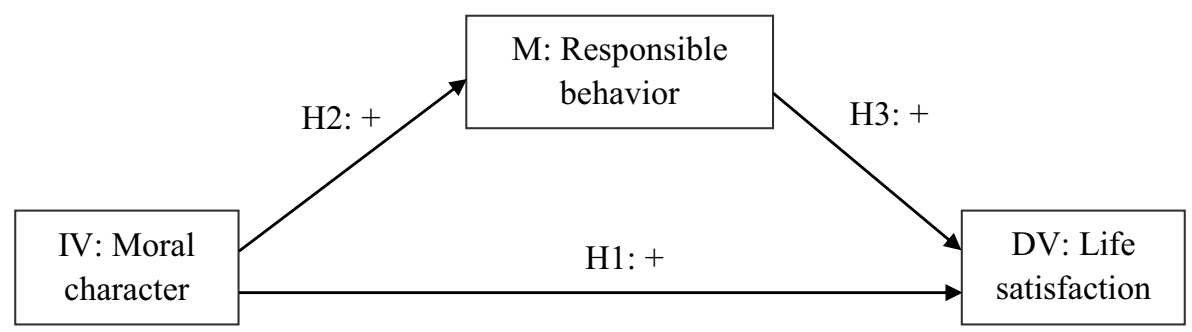

Fig. 1 Hypothesized relationships among moral character, responsible behavior, and life satisfaction. IV $=$ Independent variable; $\mathrm{M}=$ Mediator $\mathrm{DV}=$ Dependent variable 
conducted to investigate the effect of each moral character factor. Third, to further examine the proposed mediation model in a holistic manner, we also performed path analysis, which included the three factors of moral character, responsible variable, and life satisfaction in one single model. This analysis was conducted using Mplus 8.0. Indices, including CFI, NNFI, RMSEA, and SRMR, were utilized to test model fit. The criteria for an acceptable model fit were a) CFI and NNFI higher than 0.90 and b) RMSEA and SRMR lower than 0.80 (Kline 2015). In both PROCESS and path analyses, bootstrapping with 5,000 times of resampling was performed, and BC 95\% CIs (i.e., bias-corrected $95 \%$ confidence intervals) were calculated.

\section{Results}

\subsection{Dimensionality of Measures of Moral Character Attributes, Adolescents' Responsible Behavior, and Life Satisfaction}

To test the dimensionality of the 25-item Personal Moral Character Scale (PMCS), we split the present sample into two sub-samples randomly and evenly for doing EFA and CFA, respectively. EFA was performed through a "principal-components analysis" with "varimax rotation". Inspection of the eigenvalues, scree plot as well as factor loadings (higher than 0.40) revealed that three factors corresponding to the original conceptual model accounted for the 25 items adequately with $49.66 \%$ of the variance explained. CFA further demonstrated that the three-dimensional structure of the moral character had good fit $(\chi 2=1038.55, d f=267, \chi 2 / d f=3.89$, "Comparative-Fit Index, CFI" =0.92, "Non-Normed fit index, NNFI" =0.91, "Root Mean Square Error of Approximation, RMSEA" = 0.05, and "Standardized Root Mean Square Residual, SRMR" $=0.04$ ). The average factor loading was $0.65,0.62$, and 0.62 , respectively, for the three factors. The three factors were closely associated with each other, with correlation coefficients ranged between 0.84 to 0.86 . The findings on the factor loadings for the items on this scale can be seen in Table 1 .

For the Adolescents' Responsible Behavior Scale (ARBS), a CFA analysis showed that the single-factor model of responsible behavior fitted the data well

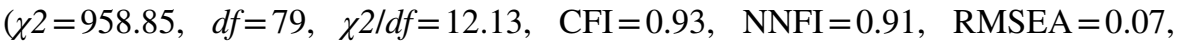
$\mathrm{SRMR}=0.05$ ). The average factor loading of the fifteen items was 0.56. For the measurement of life satisfaction, analysis using CFA showed that the singlefactor structure fitted the data well $\left(\chi^{2}=23.36, d f=5, \chi^{2} / d f=4.67, \mathrm{CFI}=0.99\right.$, $\mathrm{NNFI}=0.98, \mathrm{RMSEA}=0.05, \mathrm{SRMR}=0.01)$. The average factor loading of the five items was 0.75 .

\subsection{Relationships amongst Moral Character Attributes, Responsible Behavior, and Life Satisfaction}

Results in Table 2 show significant and positive correlations among the three factors of moral character, responsible behavior, and life satisfaction. Besides, younger adolescents tended to have higher levels of responsible behavior and life satisfaction. 
Table 1 Standardized factor loadings of items in the moral character scale in CFA

\begin{tabular}{|c|c|c|c|c|}
\hline \multirow{2}{*}{$\begin{array}{l}\text { Factor } \\
\text { 1. Treating others well }\end{array}$} & \multicolumn{2}{|c|}{ Items } & \multirow{2}{*}{$\begin{array}{l}\begin{array}{l}\text { Standardized fac- } \\
\text { tor loading }\end{array} \\
.69\end{array}$} & \multirow{2}{*}{$\begin{array}{l}\text { SE } \\
.02\end{array}$} \\
\hline & 2 & Friendly & & \\
\hline & 3 & Generous & .60 & .02 \\
\hline & 4 & Helpful & .69 & .02 \\
\hline & 7 & Kind & .72 & .02 \\
\hline & 8 & Respect others & .69 & .02 \\
\hline & 10 & Dedication & .60 & .02 \\
\hline & 12 & Caring & .70 & .02 \\
\hline & 13 & Compassionate & 67 & .02 \\
\hline & 14 & Have self-esteem & .49 & .03 \\
\hline & 18 & Sincere & .70 & .02 \\
\hline \multirow[t]{8}{*}{ 2. Self-discipline and law-abiding } & 1 & Fair & .60 & .02 \\
\hline & 5 & Hardworking & .55 & .02 \\
\hline & 6 & Honest & .63 & .02 \\
\hline & 9 & law-abiding & .59 & .02 \\
\hline & 11 & Self-discipline & .61 & .02 \\
\hline & 15 & Modest & .67 & .02 \\
\hline & 16 & Simple and unadorned & .61 & .02 \\
\hline & 17 & Educated & .72 & .02 \\
\hline \multirow[t]{7}{*}{ 3. Traditional Chinese virtues } & 19 & Polite & .68 & .02 \\
\hline & 20 & Loyal & .69 & .02 \\
\hline & 21 & Sense of responsibility & .69 & .02 \\
\hline & 22 & Forgiving & .60 & .03 \\
\hline & 23 & Sense of justice & .63 & .03 \\
\hline & 24 & Respect the elderly & .57 & .03 \\
\hline & 25 & Respect traditional culture & .45 & .03 \\
\hline
\end{tabular}

All factor loadings were significant $(p<.001)$

Furthermore, female adolescents reported higher levels of moral character and responsible behavior than did male peers. However, girls reported a lower level of life satisfaction than did boys. While family economic status was not significantly correlated with adolescents' moral character, responsible behavior, and life satisfaction, those living in intact families displayed more responsible behavior and greater life satisfaction.

\subsection{Predictive Effects of Moral Character Qualities and Adolescents' Responsible Behavior}

Results of mediation effect analyses through PROCESS and path analysis through Mplus are presented in Table 3. Four observations can be highlighted in Table 3. 


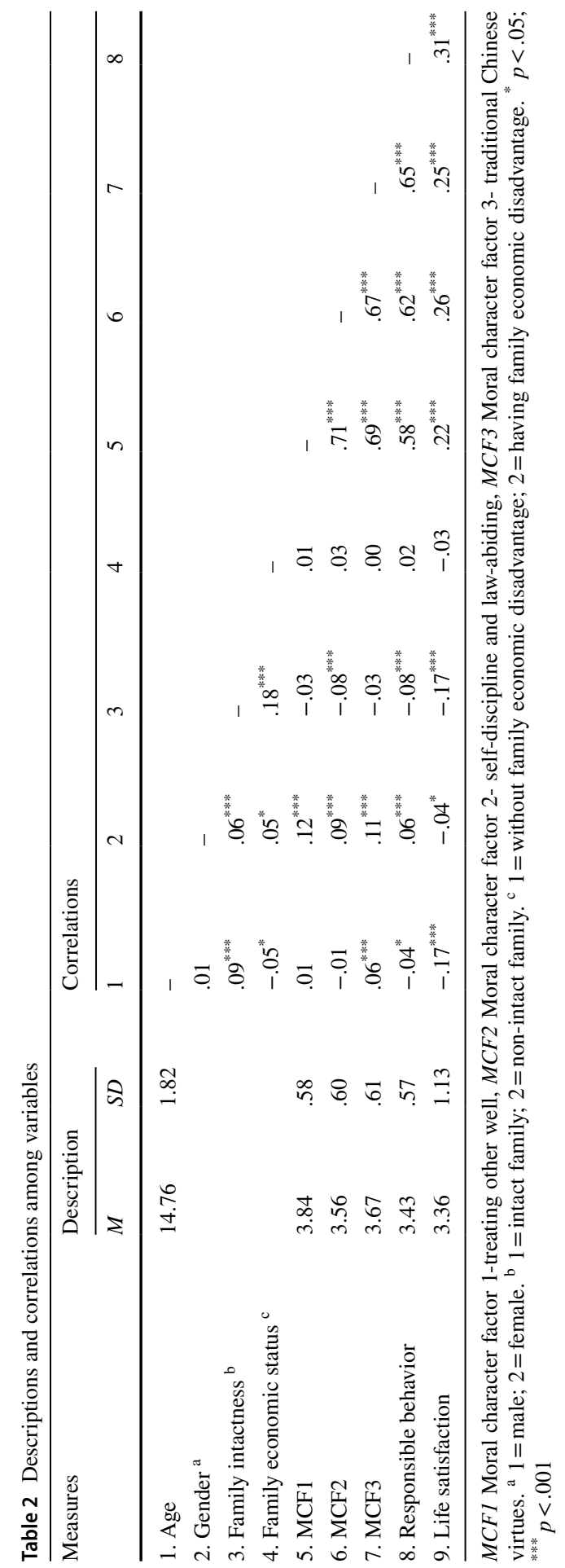




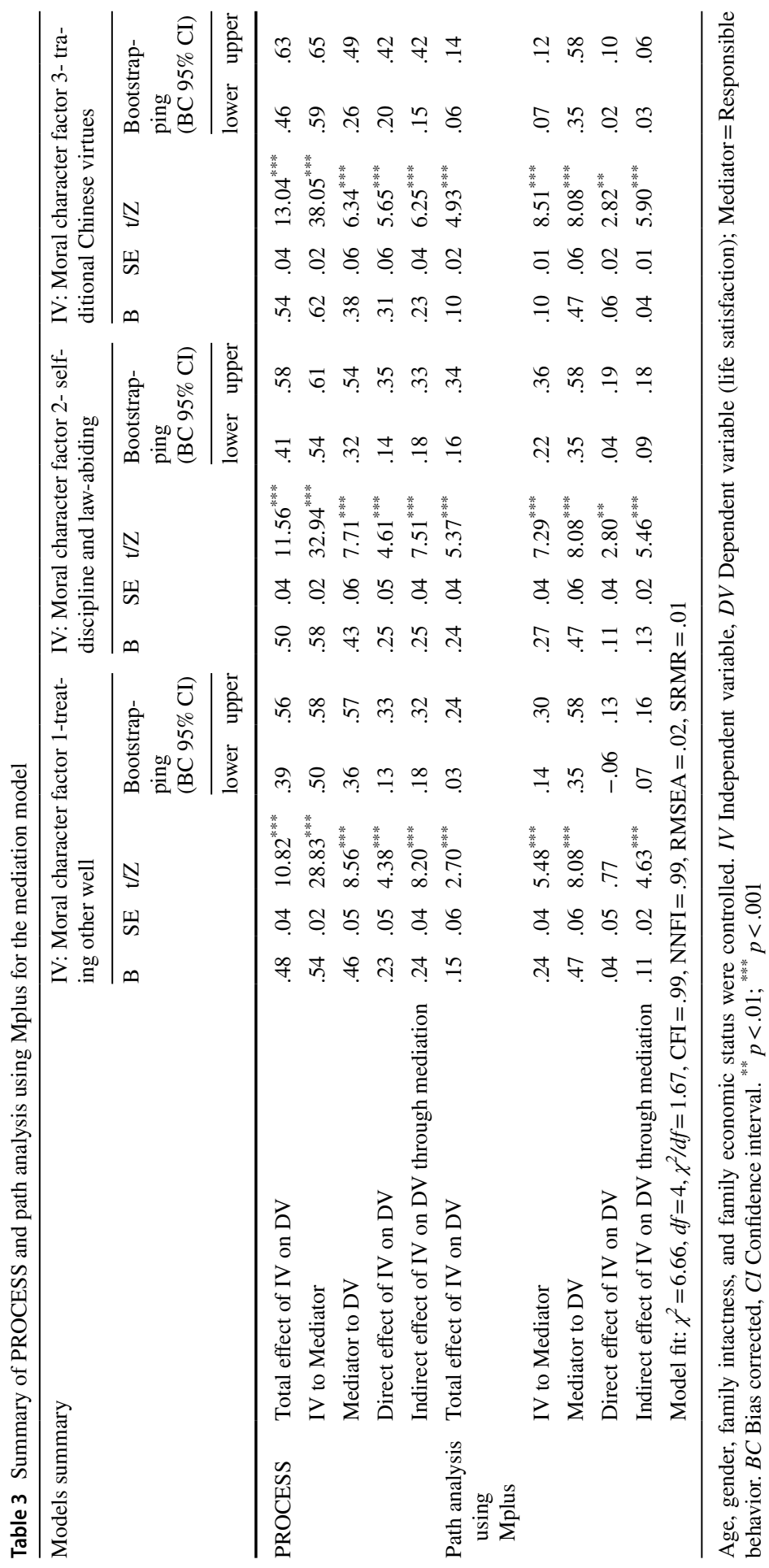


First, each factor of the moral character showed a significant and positive effect on life satisfaction (i.e., direct effect), providing support for Hypothesis 1. Second, all three factors of moral character showed significant and positive predictive effects on responsible behavior, providing support for Hypothesis 2. Third, responsible behavior also showed a significant and positive effect on life satisfaction, providing support for Hypothesis 3. Finally, the indirect effects of the three factors of moral character on life satisfaction via responsible behavior were also significant, supporting the mediation model (Hypothesis 4).

For the combined picture based on SEM using Mplus, Fig. 2 shows the standardized regression coefficients. The standardized regression coefficients of the paths from moral character factors to responsible behavior ranged between 0.25 and $0.42(p<0.001)$ and responsible behavior further predicted adolescent life satisfaction $(\beta=0.23, p<0.001)$. While the direct paths from self-discipline and law-abiding (i.e., the second dimension of moral character, $\beta=0.08, p<0.01$ ) as well as traditional Chinese virtues (i.e., the third dimension of moral character, $\beta=0.08, p<0.01)$ to life satisfaction were also significant, the direct predictive effect of treating others well (i.e., the first dimension of moral character) on life satisfaction was not $(\beta=0.02, p=0.44)$. Overall speaking, the findings suggest that adolescents' moral attributes can drive them to do better in filling their duties and responsibilities, which in turn leads to a higher level of life satisfaction.

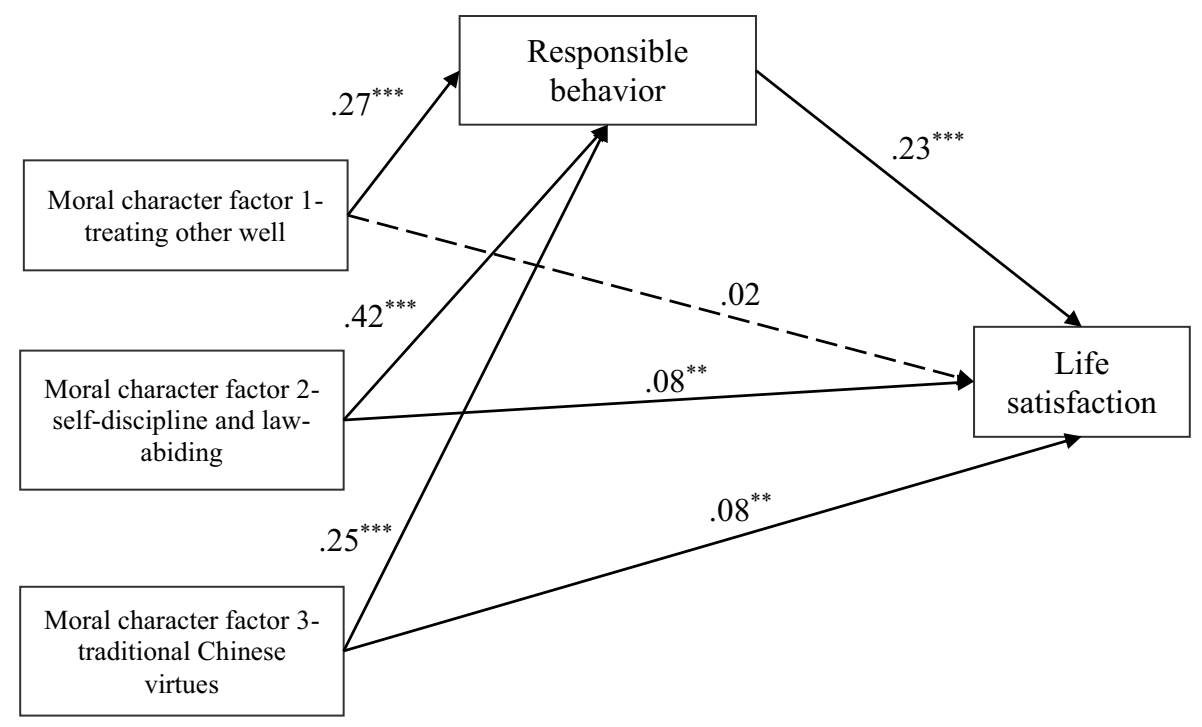

Fig. 2 Standardized results of path analysis using Mplus on the relationships among adolescent moral character, responsible behavior, and their life satisfaction. Age, gender, family intactness, and family economic status were controlled. $\chi 2=6.66, \mathrm{df}=4, \chi 2 / \mathrm{df}=1.67, \mathrm{CFI}=.99$, NNFI $=.99$, RMSEA $=.02$, $\mathrm{SRMR}=.01 . * * p<.01 . * * * p<.001$ 


\section{Discussion}

The present study tested the influence of moral character on adolescent well-being with the expectation that responsible behavior would be the mediator between the two constructs. Results showed that Hong Kong Chinese adolescents' moral attributes positively predicted responsible behavior, which in turn positively predicted life satisfaction. This study has several unique contributions to the existing literature. First, to the best of our knowledge, this study is a pioneer in examining moral character, social responsibility, and life satisfaction in one single study. It is also the first study testing the mediating role of adolescent social responsibility. Second, this is the first known study in this field in different Chinese contexts. Because most of the related studies have been conducted in Western societies, the present findings provide an additional perspective from a non-Western context. Third, in contrast to some previous studies in which a small sample was used, we employed a large sample in this study. Finally, we developed a 3-factor measure of moral character attributes, which shows excellent factorial validity and internal consistency.

Regarding the dimensionality of the 25-item moral character attributes scale, the findings provide support for its factorial validity that there are three aspects of moral character, including treating others well, self-discipline and law abidance, and moral character attributes in terms of traditional Chinese virtues. These findings are consistent with the literature on moral character traits. With reference to Schwartz's (1992) model, the three dimensions are similar to the "benevolence", "conformity", and "tradition" domains. Using the 24 character strengths model (Peterson and Seligman 2004) as the reference, the dimension on "treating others well" corresponds to "humanity" (such as love and kindness), and the dimension of "self-restraint and law abidance" corresponds to "justice" (e.g., fairness). Finally, confirmatory factor analyses also showed that a single factor underlines the five items assessing life satisfaction.

The findings support the hypotheses of the study. First, consistent with the previous research findings (Moreira et al. 2015), we found that moral character attributes were positively associated with adolescent well-being (Hypothesis 1). Second, in line with the previous studies that moral character attributes contribute to prosocial behavior (e.g., Hardy et al. 2014), the present study provided support for Hypothesis 2. Third, the findings gave support for Hypothesis 3, which are consistent with the previous findings that prosocial behavior influences life satisfaction (e.g., Brethel-Haurwitz and Marsh 2014). The present findings are also consistent with the findings that PYD attributes were related to life satisfaction. For example, Soares et al. (2019) showed that several developmental assets, including caring, equality and social justice, integrity, responsibility, and restraint, were positively associated with life satisfaction. Similar findings on the contribution of PYD attributes to life satisfaction were also reported by Lin and Shek (2019) and Zhu and Shek (2020b).

Finally, an innovative finding of the study is that responsible behavior is a mediator of the influence of moral character attributes on life satisfaction. One 
possible explanation for the mediating effect of responsible behavior on the influence of moral character on life satisfaction is that moral character attributes might constitute an "inner motive" driving a person to act in a responsible way, which eventually results in higher subjective well-being indexed by life satisfaction. However, although PROCESS analyses showed that the direct effect of moral attributes on life satisfaction was found for all three moral attributes measures, full mediation of the influence of "treating others well" on life satisfaction was not found under Mplus analyses. Further studies should be conducted to clarify this interesting observation in the future.

There are several theoretical implications of the findings. First, the findings reinforce the view that moral character is the foundation of human behavior. As pointed out by Prentice et al. (2019), morality is central to "important life events, responsiveness to circumstances, and implications for well-being" (p. 456). Indeed, many philosophers have argued that moral character plays an important role in shaping human behavior. In the Chinese culture, strong emphasis is placed on moral character of an individual, as exemplified in the saying of "xiūshēn, qíjiā, zhìguó, píngtiānxià" ("before you bring peace to the world, you have to rule a country; before you rule a country, you have to harmonize your family; before you harmonize yourself, you have to cultivate your character"). Unfortunately, moral character attributes have not been given proper attention in the scientific literature, probably because of the legacy of behavioral science that "non-observables" should not be studied.

Second, the present findings support the claims of PYD theories in the field. With reference to the developmental assets models (e.g., Benson et al. 2011), moral character attributes and responsible behavior can be subsumed under "positive values". Moral character attributes and responsible behavior are also subsumed under "character" in the 5C/6C model of Richard Lerner. In the PYD framework, the general proposition is that PYD attributes would promote the well-being of adolescents (Benson et al. 2006). The total effects contributed by moral character attributes and responsible behavior are also consistent with the PYD theoretical proposition that the effects of PYD are additive in nature (Soares et al. 2019). The present findings are also consistent with the observation that PYD attributes are negatively related to adolescent depression (Zhou et al. 2020a) and measures of well-being (Zhou et al. $2020 \mathrm{~b}$ ). As there are few related studies in the PYD literature, particularly in the Chinese context (Qi et al. 2020), the present findings are constructive responses.

Third, the present findings suggest that the influence of moral character attributes on life satisfaction is quite universal across Western and non-Western contexts. This observation is important because these are studies showing that the relationship between personal values and life satisfaction was moderated by socio-economic conditions (Sortheix and Lönnqvist 2014) and whether virtues were appreciated by the society or not (Stavrova et al. 2013).

Finally, the findings suggest that besides possessing moral character attributes, performing responsible behavior is an essential factor in adolescent life satisfaction. This finding is in line with the view of PYD theories that engagement in prosocial behavior contributes to adolescent well-being. Interestingly, this finding is consistent with the Biblical saying that "even so faith, if it has no works, is dead in itself" (Jacob 2:17) and the Chinese sayings that "zhī ér xíng zé shàn, 
zhī ér bù xíng zé chǐ" ("it is good to act after one knows, it is shameful not to act even one knows") and "zhī xíng hé ȳ̄" ("unity of knowledge and behavior").

Practically speaking, the findings suggesting that the promotion of moral character attributes is a promising way to promote well-being in adolescence. This is important because adolescent life satisfaction is prone to drop slightly during adolescence in Western and Asian societies (e.g., Chang et al. 2003; Suldo and Huebner 2004; Shek and Liang 2018). Moral competence is also an important domain of life skills (Shek et al. 2020). Providing opportunities for adolescents to learn and act on moral principles do not only improve moral identity (Hardy and Carlo 2011), but also increase life satisfaction, as suggested by the present study.

In addition, fostering adolescents' moral character is important because the world is undergoing a series of political and social changes, and young people are historically actively involved in social movements. One recent example is the protests in Hong Kong (2019-2020). Shek (2020) pointed out that the lack of emphasis on moral and holistic education is one of the fuels of the Hong Kong social unrest, which consequently hampered the quality of life of citizens in Hong Kong. In a recent review, Leung and Shek (2021) revealed that the challenges for moral education in Hong Kong still exists, and moral education should incorporate developmental models such as PYD theories. Therefore, the findings of this paper echo the importance of cultivating character attributes and social responsibility in adolescents. It is argued that adoption of PYD programs such as the "Project P.A.T.H.S." in Hong Kong would be helpful to foster holistic development in adolescents in Hong Kong, including their moral competence and prosocial behavior (Ma et al. 2019; Shek and Zhu 2020).

Although the study is pioneering in the international and Chinese contexts, it has several limitations. First, as the data collected are cross-sectional in nature, we should be cautious in assessing the cause-effect relationships amongst moral character attributes, responsible behavior, and life satisfaction. Second, we used convenience sampling in the present study, which might limit the representation and diversity of the sample. Third, the data utilized in the present study were collected by self-reporting questionnaires, which are prone to social desirability bias. However, self-reporting questionnaires have been commonly used by many researchers in the field (Gunnoe et al. 1999; Hardy et al. 2014; Wray-Lake et al. 2016). Studies also showed that self-reporting responsible behavior is a valid measure of actual behavior in reality (Ford et al. 1989; Starrett 1996; Nakamura and Watanabe-Muraoka 2006). Nevertheless, future studies will benefit by collecting data from multiple informants. Fourth, the participants in the current study are all Hong Kong adolescents, whether the findings could be generalized to a larger context, such as mainland China should be explored in future studies. Lastly, we developed the measure of moral character based on the local culture and values in Hong Kong. Future studies should be conducted to examine its psychometric properties in other cultural contexts.

Acknowledgements This paper and the series of studies on moral education in Hong Kong are financially supported by Wofoo Foundation. 
Open Access This article is licensed under a Creative Commons Attribution 4.0 International License, which permits use, sharing, adaptation, distribution and reproduction in any medium or format, as long as you give appropriate credit to the original author(s) and the source, provide a link to the Creative Commons licence, and indicate if changes were made. The images or other third party material in this article are included in the article's Creative Commons licence, unless indicated otherwise in a credit line to the material. If material is not included in the article's Creative Commons licence and your intended use is not permitted by statutory regulation or exceeds the permitted use, you will need to obtain permission directly from the copyright holder. To view a copy of this licence, visit http://creativecommons.org/licen ses/by/4.0/.

\section{References}

Alden, L. E., \& Trew, J. L. (2013). If it makes you happy: Engaging in kind acts increases positive affect in socially anxious individuals. Emotion, 13, 64-75. https://doi.org/10.1037/a0027761.

Aquino, K., \& Reed, A. (2002). The self-importance of moral identity. Journal of Personality and Social Psychology, 83, 1423-1440. https://doi.org/10.1037//0022-3514.83.6.1423.

Benson, P. L., Scales, P. C., Hamilton, S. F., \& Sesma, A., Jr. (2006). Positive youth development: Theory, research and applications. In W. Damon \& R. M. Lerner (Eds.), Handbook of child psychology. Theoretical models of human development (pp. 894-941). New York: Wiley.

Benson, P. L., Scales, P. C., \& Syvertsen, A. K. (2011). The contribution of the developmental assets framework to positive youth development theory and practice. Advances in Child Development \& Behavior, 41(18), 197-230. https://doi.org/10.1016/b978-0-12-386492-5.00008-7.

Berkowitz, L., \& Lutterman, K. G. (1968). The traditional socially responsible personality. Public Opinion Quarterly, 32, 169-185. https://doi.org/10.1086/267597.

Berman, S. (1997). Children's social consciousness and the development of social responsibility. New York: State University of New York Press.

Blasi, A. (1993). The development of identity: Some implications for moral functioning. In G. G. Naom \& T. E. Wren (Eds.), The moral self (pp. 99-122). Cambridge: MIT Press.

Brethel-Haurwitz, K. M., \& Marsh, A. A. (2014). Geographical differences in subjective well-being predict extraordinary altruism. Psychological Science, 25, 762-771. https://doi.org/10.1177/09567 97613516148 .

Centre for Governance and Citizenship (2004). Duties and responsibilities of Hong Kong students. https ://me.icac.hk/upload/doc/j442.html. Accessed 8 Jan 2020.

Chai, X., Wang, J., Li, X., Liu, W., Zhao, G., \& Lin, D. (2020). Development and validation of the Chinese Positive Youth Development Scale. Applied Developmental Science, 1-14, https://doi. org/10.1080/10888691.2020.1712206.

Chang, L., McBride-Chang, C., Stewart, S. M., \& Au, E. (2003). Life satisfaction, self-concept, and family relations in Chinese adolescents and children. International Journal of Behavioral Development, 27, 182-189. https://doi.org/10.1080/01650250244000182.

Chen, L. (2008). Characters of adolescents' values and related research (Unpublished master thesis). PR China (in Chinese): Shanghai Normal University.

Chiou, J. S. (2001). Horizontal and vertical individualism and collectivism among college students in the United States, Taiwan, and Argentina. The Journal of Social Psychology, 141(5), 667-678. https:// doi.org/10.1080/00224540109600580.

Chopik, W. J., Newton, N. J., Ryan, L. H., Kashdan, T. B., \& Jarden, A. J. (2017). Gratitude across the life span: Age differences and links to subjective well-being. The Journal of Positive Psychology, 3(14), 292-302.

Cloninger, C. R. (2004). Feeling good: The science of well-being. New York: Oxford University Press.

Cloninger, C. R. (2008). On well-being: Current research trends and future directions. Mens Sana Monograph, 6, 3-9. https://doi.org/10.4103/0973-1229.40564.

Cloninger, C. R., Svrakic, D. M., \& Przybeck, T. R. (1993). A psychobiological model of temperament and character. Archives of General Psychiatry, 50(12), 975-990. https://doi.org/10.1001/archp syc.1993.01820240059008. 
Costa, P. T., \& McCrae, R. R. (1980). Influence of extraversion and neuroticism on subjective well-being: Happy and unhappy people. Journal of Personality and Social Psychology, 38, 668-678. https://doi. org/10.1037/0022-3514.38.4.668.

Cotney, J. L., \& Banerjee, R. (2019). Adolescents' conceptualizations of kindness and its links with wellbeing: A focus group study. Journal of Social and Personal Relationships, 36(2), 599-617. https:// doi.org/10.1177/0265407517738584.

Damon, W., \& Hart, D. (1992). Self-understanding and its role in social and moral development. In M. Bornstein \& M. E. Lamb (Eds.), Developmental psychology: An advanced textbook (3rd ed., pp. 421-464). Hillsdale: Erlbaum.

DeNeve, K. M., \& Cooper, H. (1998). The happy personality: A meta-analysis of 137 personality traits and subjective well-being. Psychological Bulletin, 124(2), 197-229. https://doi. org/10.1037/0033-2909.124.2.197.

Diener, E. (1996). Traits can be powerful, but are not enough: Lessons from subjective well-being. Journal of Research in Personality, 30, 389-399. https://doi.org/10.1006/jrpe.1996.0027.

Diener, E., Emmons, R. A., Larsen, R. J., \& Griffin, S. (1985). The satisfaction with life scale. Journal of Personality Assessment, 49, 71-75. https://doi.org/10.1207/s15327752jpa4901_13.

Diener, E., Suh, E. M., Lucas, R. E., \& Smith, H. L. (1999). Subjective well-being: Three decades of progress. Psychological Bulletin, 125, 276-302.

Dou, K., Li, J., Wang, Y., Li, J., Liang, Z., \& Nie, Y. (2019). Engaging in prosocial behavior explains how high self-control relates to more life satisfaction: Evidence from three Chinese samples. PLoS ONE, 14(10), e0223169. https://doi.org/10.1371/journal.pone.0223169.

Emmons, R. A., \& Diener, E. (1985). Personality correlates of subjective well-being. Personality and Social Psychology Bulletin, 11, 89-97. https://doi.org/10.1177/0146167285111008.

Ford, M. E., Wentzel, K. R., Wood, D., Stevens, E., \& Siesfeld, G. A. (1989). Processes associated with integrative social competence: Emotional and contextual influences on adolescent social responsibility. Journal of Adolescent Research, 4(4), 405-425.

Gallay, L. S. (2006). Social responsibility. In L. Sherrod, C. A. Flanagan, R. Kassimir, \& A. K. Syvertsen (Eds.), Youth activism: An international encyclopedia (pp. 599-602). Westport: Greenwood Publishing.

Garcia, D. (2011). Two models of personality and well-being among adolescents. Personal and Individual Differences, 50, 1208-1212.

Garcia, D., Andersson, A. A., \& Archer, T. (2015). Editorial: Character, responsibility, and well-being: influences on mental health and constructive behavior patterns. Frontiers in Psychology, 6, 01079. https://doi.org/10.3389/fpsyg.2015.01079.

Gunnoe, M. L., Hetherington, E. M., \& Reiss, D. (1999). Parental religiosity, parenting style, and adolescent social responsibility. Journal of Early Adolescence, 19(2), 199-225.

Hardy, S. A., \& Carlo, G. (2011). Moral identity: What is it, how does it develop, and is it linked to moral action? Child Development Perspectives, 5(3), 212-218. https://doi.org/10.111 1/j.1750-8606.2011.00189.x.

Hardy, S. A., Walker, L. J., Olsen, J. A., Woodbury, R. D., \& Hickman, J. R. (2014). Moral identity as moral ideal self: Links to adolescent outcomes. Developmental Psychology, 50, 45-57. https://doi. org/10.1037/a0033598.

Hayes, A. F. (2018). Introduction to mediation, moderation, and conditional process analysis: A regression-based approach (2nd ed.). New York: Guilford Press.

Howell, R. T., Kern, M. L., \& Lyubomirsky, S. (2007). Health benefits: Meta-analytically determining the impact of well-being on objective health outcomes. Health Psychology Review, 1, 83-136. https ://doi.org/10.1080/17437190701492486.

Josefsson, K., Cloninger, C. R., Hintsanen, M., Jokela, M., Pulkki-Raback, L., \& Keltikangas-Järvinen, L. (2011). Associations of personality profiles with various aspects of well-being: A population-based study. Journal of Affective Disorder, 133, 265-273. https://doi.org/10.1016/j.jad.2011.03.023.

Karabati, S., \& Cemalcilar, Z. (2010). Values, materialism, and well-being: A study with Turkish university students. Journal of Economic Psychology, 31, 624-633.

Kline, R. B. (2015). Principles and practice of structural equation modeling (4th ed.). New York: The Guilford Press.

Lerner, R. M., Lerner, J. V., Lewin-Bizan, S., Bowers, E. P., Boyd, M. J., Mueller, M. K., et al. (2011). Positive youth development: Processes, programs, and problematics. Journal of Youth Development, 6, 38-62. https://doi.org/10.5195/JYD.2011.174. 
Leung, J. T. Y., \& Shek, D. T. L. (2021). Moral education, character education and citizenship education policies in Hong Kong: A critical review. International Public Health Journal (in press).

Lin, L., \& Shek, D. T. L. (2019). Does service leadership education contribute to student well-being? A quasi-experimental study based on Hong Kong university students. Applied Research in Quality of Life, 14(5), 1147-1163. https://doi.org/10.1007/s11482-018-9644-x.

Liu, X., Lv, Y., Ma, Q., Guo, F., Yan, X., \& Ji, L. (2016). The basic features and patterns of character strengths among children and adolescents in China (in Chinese). Studies of Psycholy and Behavior, 14, 167-176.

Ma, C. M. S., Shek, D. T. L., \& Chen, J. M. T. (2019). Changes in the participants in a community-based positive youth development program in Hong Kong: Objective outcome evaluation using a onegroup pretest-posttest design. Applied Research Quality Life, 14(4), 961-979.

Marks, G. N., \& Fleming, N. (1999). Influences and consequences ofwell-being among Australian young people: 1980-1995. Social Indicators Research, 46, 301-323. https://doi.org/10.1023/A:10069 28507272.

Martínez-Martí, M. L., \& Ruch, W. (2014). Character strengths and well-being across the life span: Data from a representative sample of German-speaking adults living in Switzerland. Frontiers in Psychology, 5, e1253. https://doi.org/10.3389/fpsyg.2014.01253.

Moreira, P. A. S., Cloninger, R. C., Dinis, L., Sá, L., Oliveira, J. T., Dias, A., \& Oliveira, J. (2015). Personality and well-being in adolescents. Frontiers in Psychology, 5, 1-15. https://doi. org/10.3389/fpsyg.2014.01494.

Nakamura, M., \& Watanabe-Muraoka, A. M. (2006). Global social responsibility: Developing a scale for senior high school students in Japan. International Journal for the Advancement of Counselling, 28(3), 213-226.

O'Connell, B. H., O’Shea, D., \& Gallagher, S. (2015). Enhancing social relationships through positive psychology activities: A randomised controlled trial. The Journal of Positive Psychology, 11, 1-14. https://doi.org/10.1080/17439760.2015.1037860.

Park, N. (2004). Character strengths and positive youth development. Annals of the American Academy of Political and Social Science, 59, 40-54. https://doi.org/10.1177/0002716203260079.

Park, N., \& Peterson, C. (2006). Moral competence and character strengths among adolescents: the development and validation of the values in action inventory of strengths for youth. Journal of Adolescence, 29, 891-909. https://doi.org/10.1016/j.adolescence.2006.04.011.

Peterson, C., \& Seligman, M. E. P. (2004). Character strengths and virtues: A handbook and classification. New York: Oxford University Press.

Porubanova-Norquist, M. (2012). Character as a predictor of life satisfaction in Czech adolescent sample: 3-Year follow-up study. Personality and Individual Differences, 53(3), 231-235. https:// doi.org/10.1016/j.paid.2012.03.022.

Pratt, M. W., Arnold, M. L., \& Lawford, H. (2009). Growing towards care: A narrative approach to prosocial moral identity and generativity of personality in emerging adulthood. In D. Narvaez \& D. K. Lapsley (Eds.), Personality, identity, and character: Explorations in moral psychology (pp. 295-315). New York: Cambridge University Press. https://doi.org/10.1017/CBO978051162712 5.014 .

Prentice, M., Jayawickreme, E., Hawkins, A., Hartley, A., Furr, R. M., \& Fleeson, W. (2019). Morality as a basic psychological need. Social Psychological and Personality Science, 10(4), 449-460. https://doi.org/10.1177/1948550618772011.

Qi, S., Hua, F., Zhou, Z., \& Shek, D. T. L. (2020). Trends of positive youth development publications (1995-2020): A scientometric review. Applied Research in Quality of Life. https://doi. org/10.1007/s11482-020-09878-3.

Schwartz, S. H. (1992). Universals in the content and structure of values: Theory and empirical tests in 20 countries. In M. Zanna (Ed.), Advances in experimental social psychology (Vol. 25) (pp. 1-65). New York: Academic Press.

Schwartz, S. H., \& Sortheix, F. M. (2018). Values and subjective well-being. In E. Diener, S. Oishi, \& L. Tay (Eds.), Handbook of well-being (pp. 1-19). Salt Lake City: DEF Publishers.

Schwartz, S. H., \& Shalom, H. (2009). Draft users manual: Proper use of the Schwarz Value Survey, version 14 January 2009, compiled by Romie F. Littrell. Auckland: Centre for Cross Cultural Comparisons. http://www.crossculturalcentre.homestead.com. Accessed 23 Apr 2020.

Seligman, M. E. (2002). Authentic happiness. New York: Free Press.

Seligman, M. E., \& Csikszentmihalyi, M. (2000). Positive psychology: An introduction. American Psychologist, 55, 5-14. https://doi.org/10.1007/978-3-319-38779-6_3. 
Shek, D. T. L. (2020). Protests in Hong Kong (2019-2020): A perspective based on quality of life and well-being. Applied Research in Quality of Life, 15(3), 619-635.

Shek, D. T. L., \& Liang, L. Y. (2018). Psychosocial factors influencing individual well-being in Chinese adolescents in Hong Kong: A six-year longitudinal study. Applied Research in Quality of Life, 13(3), 561-584. https://doi.org/10.1007/s11482-017-9545-4.

Shek, D. T. L., \& Zhu, X. (2019). Reciprocal relationships between moral competence and externalizing behavior in junior secondary students: A longitudinal study in Hong Kong. Frontiers in Psychology, 10, 528. https://doi.org/10.3389/fpsyg.2019.00528.

Shek, D. T. L., \& Zhu, X. (2020). Promotion of thriving among Hong Kong Chinese adolescents: Evidence from eight-wave data. Research on Social Work Practice, 30(8), 870-883.

Shek, D. T. L., Yu, L., \& Fu, X. (2013). Confucian virtues and Chinese adolescent development: a conceptual review. International Journal of Adolescent Medicine and Health, 25, 335-344. https ://doi.org/10.1515/ijamh-2013-0031.

Shek, D. T. L., Yu, L., Wu, F. K. Y., Zhu, X., \& Chan, K. H. Y. (2017). A 4-year longitudinal study of well-being of Chinese university students in Hong Kong. Applied Research in Quality of Life, 12, 867-884. https://doi.org/10.1007/s11482-016-9493-4.

Shek, D. T. L., Zhu, X., Leung, J. T. Y., Lee, T. Y., \& Wu, F. K. Y. (2019). Evaluation of the Project P.A.T.H.S. in mainland China: Findings based on student diaries. Research on Social Work Practice, 29(4), 410-419. https://doi.org/10.1177/1049731517745994.

Shek, D. T. L., Lin, L., Ma, C. M. S., Yu, L., Leung, J. T. Y., Wu, F. K. Y., et al. (2020). Perceptions of adolescents, teachers and parents of life skills education and life skills in high school students in Hong Kong. Applied Research in Quality of Life. https://doi.org/10.1007/s11482-020-09848-9.

Soares, A. S., Pais-Ribeiro, J. L., \& Silva, I. (2019). Developmental assets predictors of life satisfaction in adolescents. Frontiers in Psychology, 10, 1-11. https://doi.org/10.3389/fpsyg.2019.00236.

Sortheix, F. M., \& Lönnqvist, J. E. (2014). Personal value priorities and life satisfaction in Europe: The moderating role of socioeconomic development. Journal of Cross-Cultural Psychology, 45(2), 282299. https://doi.org/10.1177/0022022113504621.

Sortheix, F. M., \& Schwartz, S. H. (2017). Values that underlie and undermine well-being: Variability across countries. European Journal of Personality, 31(2), 187-201.

Sortheix, F. M., Olakivi, A., \& Helkama, K. (2013). Values, life events, and health: A study in a Finnish rural community. Journal of Community \& Applied Social Psychology, 23(4), 331-346.

Starrett, R. H. (1996). Assessment of global social responsibility. Psychological Reports, 78, 535-554.

Stavrova, O., Schlösser, T., \& Fetchenhauer, D. (2013). Are virtuous people happy all around the world? Civic virtue, antisocial punishment, and subjective well-being across cultures. Personality and Social Psychology Bulletin, 39(7), 927-942. https://doi.org/10.1177/0146167213485902.

Stoeber, J., \& Yang, H. (2016). Moral perfectionism and moral values, virtues, and judgments: Further investigations. Personality and Individual Differences, 88, 6-11. https://doi.org/10.1016/j. paid.2015.08.031.

Suldo, S. M., \& Huebner, E. S. (2004). The role of life satisfaction in the relationship between authoritative parenting dimensions and adolescent problem behavior. Social Indicators Research, 66, 165195. https://doi.org/10.1023/B:SOCI.0000007498.62080.1e.

Wan, Z., \& Yang, S. (2008). The revision of moral self-identity scale for Chinese adolescents. Science of Social Psychology (in Chinese), 23(99), 41-46.

Wray-Lake, L., \& Syvertsen, A. K. (2011). The developmental roots of social responsibility in childhood and adolescence. New Directions for Child and Adolescent Development, 2011(134), 11-25. https:// doi.org/10.1002/cd.308.

Wray-Lake, L., Syvertsen, A. K., \& Flanagan, C. A. (2016). Developmental change in social responsibility during adolescence: An ecological perspective. Developmental Psychology, 52(1), 130-142. https://doi.org/10.1037/dev0000067.

Yang, H., Stoeber, J., \& Wang, Y. (2015). Moral perfectionism and moral values, virtues, and judgments: A preliminary investigation. Personality and Individual Differences, 75, 229-233. https:// doi.org/10.1016/j.paid.2014.11.040.

Zhou, Z., Shek, D. T. L., Zhu, X., \& Dou, D. (2020). Positive youth development and adolescent depression: A longitudinal study based on Mainland Chinese high school students. International Journal of Environment Research and Public Health, 17, 4457. https://doi.org/10.3390/ijerph17124457.

Zhou, Z., Shek, D. T. L., \& Zhu, X. (2020). The importance of positive youth development attributes to life satisfaction and hopelessness in mainland Chinese adolescents. Frontiers in Psychology, 11, 553313. https://doi.org/10.3389/fpsyg.2020.553313. 
Zhu, X., \& Shek, D. T. L. (2020a). The influence of adolescent problem behaviors on life satisfaction: Parent-child subsystem qualities as mediators. Child Indicators Research, 13, 1767-1789. https:// doi.org/10.1007/s12187-020-09719-7.

Zhu, X., \& Shek, D. T. L. (2020b). Predictive effect of positive youth development attributes on adolescent delinquency in mainland China. Frontiers in Psychology. https://doi.org/10.3389/fpsyg .2020 .615900 .

Publisher's Note Springer Nature remains neutral with regard to jurisdictional claims in published maps and institutional affiliations. 